\title{
Korelasi Posisi Tip Catheter Double Lumen dengan Nilai Quick of Blood pada Pemasangan CDL Tunneling Vena Jugularis Interna Kanan di RSUP Prof. Dr. R. D. Kandou
}

\author{
${ }^{1}$ Angga P. Tubagus, ${ }^{2}$ Djony E. Tjandra, ${ }^{2}$ Richard Sumangkut
}

\author{
${ }^{1}$ PPDS Ilmu Bedah Fakultas Kedokteran Universitas Sam Ratulangi Manado \\ ${ }^{2}$ Divisi Bedah Vaskuler Bagian Ilmu Bedah Universitas Sam Ratulangi/RSUP Prof. Dr. R. \\ D. Kandou Manado \\ Email: hi.angga@gmail.com
}

\begin{abstract}
Chronic kidney disease (CKD) is a global public health problem with increasing prevalence and incidence. Patients with CKD require kidney replacement therapy such as hemodialysis. The quick of blood $(\mathrm{Qb})$ value is one of the most important determinants for adequate hemodialysis. Many factors can affect the $\mathrm{Qb}$ value, inter alia the catheter tip position. It is very complex and still controversial to determine the optimal position of the catheter itself. This study was aimed to determine the correlation between the double lumen catheter tip position and $\mathrm{Qb}$ value in insertion of the right internal jugular vein $\mathrm{CDL}$ tunneling at Prof. Dr. R. D. Kandou hospital. This was a correlation analytical study with a crosssectional design. The position of the CDL tips were evaluated by using chest $\mathrm{x}$-ray and the $\mathrm{Qb}$ values were determined by using hemodyalisis machine. Data were analyzed by using pointbiserial correlation test. In total, 55 patients were included, mostly were males (56.4\%) and late elderly (41.8\%). The results showed that the average Qb value with CDL tip position in intraatrial (178.2 $\mathrm{ml} /$ minute) was slightly higher than the average $\mathrm{Qb}$ value with CDL tip position in CAJ (171.6 $\mathrm{ml} /$ minute). The bivariate analysis showed that the position of the double-lumen catheter tip had a weak positive correlation but not significant with the $\mathrm{Qb}$ value. Conclusion: There was a correlation but not statistically significant between the position of the CDL tip and the $\mathrm{Qb}$ value.
\end{abstract}

Keywords: CKD, catheter tip position, catheter double-lumen, Quick of blood

\begin{abstract}
Abstrak: Penyakit ginjal kronik (PGK) merupakan masalah kesehatan masyarakat global dengan prevalensi dan insidens yang terus meningkat. Pasien gagal ginjal memerlukan terapi pengganti ginjal seperti hemodialisis. Nilai quick of blood $(\mathrm{Qb})$ merupakan salah satu penentu yang sangat penting bagi hemodialisis yang adekuat. Banyak faktor yang dapat memengaruhi nilai $\mathrm{Qb}$, salah satunya ialah posisi tip kateter. Hal yang menentukan posisi optimal dari kateter sendiri sangat kompleks dan masih kontroversial. Penelitian ini bertujuan untuk mengetahui korelasi antara posisi tip kateter double lumen dengan nilai quick of blood pada pemasangan CDL vena jugularis interna kanan di RSUP Prof. Dr. R. D. Kandou Manado. Jenis penelitian ialah analitik korelasi dengan desain potong lintang. Alat ukur yang digunakan ialah foto toraks untuk menentukan posisi tip CDL dan mesin hemodialisa untuk melihat nilai $\mathrm{Qb}$. Data hasil penelitian dianalisis dengan uji korelasi point-biserial. Subyek penelitian ini sebanyak 55 pasien, lebih banyak yang berjenis kelamin laki-laki $(56,4 \%)$ dan berada dalam kategori usia lansia akhir $(41,8 \%)$. Hasil penelitian menunjukkan nilai rerata Qb posisi tip CDL di intraatrial (178,2 $\mathrm{ml} / \mathrm{menit})$ sedikit lebih tinggi daripada rerata nilai Qb posisi tip CDL di CAJ (171,6 ml/menit). Hasil analisis data mendapatkan korelasi positif lemah dan tidak bermakna (antara posisi tip catheter double-lumen dengan nilai Qb. Simpulan: Terdapat korelasi yang tidak bermakna secara statistik antara posisi tip CDL dengan nilai Qb.
\end{abstract}

Kata kunci: PGK, posisi tip kateter, double-lumen catheter, quick of blood 
Penyakit ginjal kronik (PGK) masih merupakan masalah kesehatan masyarakat global dengan prevalensi dan insidens gagal ginjal yang meningkat, prognosis yang buruk, dan biaya pengobatan yang tinggi. Prevalensi PGK meningkat seiring dengan meningkatnya jumlah penduduk usia lanjut dan kejadian penyakit diabetes melitus serta hipertensi. Sekitar satu dari 10 populasi global mengalami PGK pada stadium tertentu. ${ }^{1}$

Menurut hasil dari Global Burden of Disease tahun 2010, PGK merupakan penyebab kematian peringkat ke-27 di dunia tahun 1990 dan meningkat menjadi urutan ke-18 pada tahun 2010. Hasil Riskedas 2013 menunjukkan populasi usia $\geq 15$ tahun yang terdiagnosis PGK sebesar $12,5 \%$. Prevalensi PGK meningkat seiring dengan bertambahnya usia, dengan peningkatan tajam pada kelompok usia 35-44 tahun dibandingkan kelompok usia 25-34 tahun. Provinsi di Indonesia dengan prevalensi tertinggi ialah Sulawesi Tengah sebesar 0,5\%, diikuti Aceh, Gorontalo, dan Sulawesi Utara masing-masing $0,4 \%$. ${ }^{1}$

Data dari United State Renal Data System (USRDS) tahun 2015 menyatakan terdapat 124.111 kasus baru PGK stadium terminal. Pada keseluruhan kasus PGK terdapat 500.000 kasus menjalani terapi hemodialisis serta lebih dari 200.000 kasus hidup dengan transplantasi ginjal. ${ }^{2}$

Hemodialisis merupakan bentuk paling umum dari Renal Replacement Therapy di Asia, diikuti oleh hemodialisis peritoneal dan transplantasi ginjal. Hemodialisis yang adekuat sangat penting dalam menurunkan morbiditas dan mortalitas pasien. Data Indonesian Renal Registry (IRR) tahun 2016 menunjukkan PGK stadium terminal merupakan penyakit utama dengan kasus terbanyak $(89 \%)$ dan jumlah diagnosis PGK stadium terminal yang menjalani hemodialisis mencapai 18.613 kasus. Berdasarkan IRR 2016, di Sulawesi Utara tercatat sebanyak 147 kasus baru dan 45 kasus lama.,3

Central venous catheter (CVC) merupakan akses vaskuler yang sering diguna- kan dan merupakan salah satu terapi medikal yang penting. Salah satu faktor akses vaskuler yang dapat memengaruhi quick of blood $(\mathrm{Qb})$ yaitu kateter itu sendiri yang meliputi diameter kateter, posisi ujung tip kateter, bentuk tip, dan lapisan double-lumen. Hal yang menentukan posisi optimal dari tip CVC sangat kompleks dan masih kontroversial. Suatu ulasan dari literatur ilmiah dengan topik posisi tip CVC menunjukkan beberapa pendapat yang menimbulkan pertentangan dalam praktik klinik. ${ }^{4-6}$

Penelitian ini bertujuan untuk mengetahui korelasi antara posisi tip kateter double lumen dengan nilai quick of blood pada pemasangan catheter double-lumen (CDL) vena jugularis interna kanan di RSUP Prof. Dr. R. D. Kandou Manado.

\section{METODE PENELITIAN}

Jenis penelitian ini ialah analitik korelasi dengan menggunakan desain potong lintang. Penelitian ini dilaksanakan di Instalasi Hemodialisa RSUP Prof. Dr. R. D. Kandou Manado sejak bulan Agustus 2018 sampai Desember 2018. Subyek penelitian ini berjumlah 55 orang. Karakteristik subyek penelitian ialah pasien PGK stadium akhir yang menjalani hemodialisis dengan menggunakan CDL tunneling dengan pendekatan vena jugularis interna kanan dan bersedia ikut serta dalam penelitian.

Instrumen penelitian yaitu foto toraks untuk menentukan posisi tip CDL dan mesin hemodialisa untuk melihat nilai $\mathrm{Qb}$. Data dianalisis dengan menggunakan uji korelasi Point-biserial.

\section{HASIL PENELITIAN}

Tabel 1 memperlihatkan bahwa subyek penelitian lebih banyak berjenis kelamin laki-laki yaitu sebanyak 31 orang $(56,4 \%)$ sedangkan perempuan sebanyak 24 orang $(43,6 \%)$. Subyek penelitian berada pada rentang kategori usia dewasa sampai manula, terbanyak berada dalam kategori usia lansia akhir yaitu 23 orang $(41,8 \%)$ dan yang paling sedikit ialah kategori dewasa sebanyak 5 orang (9\%). 
Tabel 1. Distribusi berdasarkan karakteristik subyek penelitian

\begin{tabular}{lcc}
\hline $\begin{array}{c}\text { Karakteristik } \\
\text { subyek penelitian }\end{array}$ & n & \% \\
\hline Jenis kelamin & & \\
$\quad$ Laki-laki & 31 & 56,4 \\
Perempuan & 24 & 43,6 \\
Total & 55 & 100 \\
Usia & & \\
Dewasa & 5 & 9 \\
Lansia awal & 21 & 38,2 \\
Lansia akhir & 23 & 41,8 \\
Manula & 6 & 11 \\
Total & 55 & 100 \\
\hline
\end{tabular}

Tabel 2 memperlihatkan sebagian besar subyek penelitian memiliki posisi tip CDL di cavoatrial junction (CAJ) yaitu sebanyak
44 orang $(80 \%)$ dan yang memiliki posisi tip CDL di intraatrial yaitu sebanyak 11 orang (20\%). Nilai rerata $\mathrm{Qb}$ dengan posisi tip CDL di CAJ ialah 171,6 $\mathrm{ml} / \mathrm{menit}$ dengan nilai minimum sebesar 120 $\mathrm{ml} / \mathrm{menit}$ dan nilai maksimum sebesar 230 $\mathrm{ml} /$ menit. Nilai rerata $\mathrm{Qb}$ dengan posisi tip CDL di intraatrial ialah $178,2 \mathrm{ml} /$ menit dengan nilai minimum sebesar 140 $\mathrm{ml} / \mathrm{menit}$ dan nilai maksimum sebesar 200 $\mathrm{ml} /$ menit.

Hubungan antara posisi tip CDL dan nilai $\mathrm{Qb}$ diuji dengan korelasi Point Biserial. Hasil uji ini memperoleh $\mathrm{r}_{\mathrm{pb}}=0,101$ dengan nilai $P=0,232$, yang menyatakan adanya korelasi positif lemah dan tidak bermakna antara posisi tip CDL dengan nilai $\mathrm{Qb}(P>0,05)$.

Tabel 2. Nilai deskriptif $\mathrm{Qb}$ menurut posisi tip catheter double-lumen

\begin{tabular}{cccccc}
\hline Posisi tip CDL & n & Mean & SD & Min. & Maks. \\
\hline CAJ & 44 & 171,6 & 27 & 120 & 230 \\
\hline Intra-atrial & 11 & 178,2 & 24 & 140 & 200 \\
\hline
\end{tabular}

\section{BAHASAN}

Pada penelitian ini terdapat 55 orang subyek dengan 31 orang berjenis kelamin laki-laki dan 24 orang berjenis kelamin perempuan. Hal ini serupa dengan prevalensi dari Pusdatin 2017 yang melaporkan prevalensi PGK pada laki-laki sedikit lebih tinggi $(0,3 \%)$ daripada perempuan $(0,2 \%){ }^{1}$ Subyek penelitian paling banyak berada pada kategori usia lansia akhir (56-65 tahun) yaitu sebanyak 23 orang. Pada orang dengan usia lanjut terdapat prevalensi yang tinggi dari PGK. Usia lanjut merupakan prediktor terjadinya PGK yaitu $11 \%$ individu dengan usia $>65$ tahun tanpa penyakit penyerta seperti hipertensi dan diabetes memiliki level kreatinin yang tinggi. ${ }^{1,7}$

Subyek penelitian ini ialah pasien PGK stadium akhir yang menjalani hemodialisis menggunakan CDL tunneling dengan pendekatan vena jugularis interna kanan. Pendekatan vena jugularis interna merupakan pilihan utama dalam melakukan insersi CVC dikarenakan oleh beberapa alasan. Pertama, vena jugularis interna merupakan vena superfisial yang besar sehingga mudah divisualisasikan lewat USG. Kedua, vena jugularis interna kanan langsung secara lurus bermuara ke vena kava superior dan atrium kanan sehingga memudahkan dalam prosedur insersi. ${ }^{8}$ Penelitian oleh Les dan Wankowicz ${ }^{9}$ menunjukkan bahwa lokasi insersi yang lebih dipilih ialah vena jugularis interna khususnya vena jugularis interna kanan diikuti oleh vena femoralis dan vena subklavia. Penelitian oleh Timsit ${ }^{10}$ menunjukkan bahwa malposisi lebih jarang terjadi jika insersi CVC dilakukan dengan pendekatan vena jugularis interna kanan daripada dengan pendekatan vena subklavia.

Klinisi dapat menilai keberhasilan dari insersi CVC berdasarkan tiga hal yaitu quick of blood, flow resistance dan resirkulasi. Peningkatan nilai $\mathrm{Qb}$ dapat meningkatkan efisiensi dari hemodialisis, namun nilai Qb sendiri bukan menjadi satusatunya penentu keberhasilan hemodialisis. Teknik insersi kateter, sumber daya manusia, mesin hemodialisis, keadaan 
pasien itu sendiri, dan komplikasi pemasangan CVC menjadi faktor-faktor penentu lain yang juga berperan dalam mencapai hemodialisis yang adekuat. ${ }^{11,12}$

Quick of blood dipengaruhi oleh beberapa hal yaitu lokasi insersi, resistensi, resirkulasi, tipe dan desain kateter seperti diameter dan panjang kateter, serta posisi tip kateter. Kateter dengan diameter yang lebih besar memiliki nilai Qb lebih tinggi dibandingkan kateter dengan diameter yang lebih kecil. Peningkatan sedikit diameter dalam dari lumen arterial dan vena akan menghasilkan peningkatan yang cukup besar pada nilai $\mathrm{Qb} .{ }^{13}$ Posisi pasti dari tip kateter masih menjadi perdebatan. Posisi tip kateter biasanya berada pada cavoatrial junction (CAJ), intraatrial, dan vena kava superior. $^{14,15}$

Penelitian ini menunjukkan bahwa terdapat korelasi positif yang lemah dan tidak bermakna secara statistik antara posisi tip CDL dengan nilai $\mathrm{Qb}$ dengan nilai rerata $\mathrm{Qb}$ posisi tip $\mathrm{CDL}$ di intraatrial (178,2 $\mathrm{ml} / \mathrm{menit})$ sedikit lebih tinggi daripada rerata nilai $\mathrm{Qb}$ posisi tip CDL di CAJ (171,6 ml/menit). Perbedaan nilai rerata $\mathrm{Qb}$ posisi tip CDL di intraatrial dan di CAJ hanya sebesar $6,6 \mathrm{ml} / \mathrm{menit}(3,8 \%)$. Beberapa penelitian menunjukkan bahwa peningkatan nilai $\mathrm{Qb} 15-25 \%$ efektif dalam meningkatkan dialisis secara adekuat. ${ }^{12,16,17}$ Pada penelitian ini hanya terjadi perbedaan nilai $\mathrm{Qb}$ yang sangat kecil yaitu nilai $\mathrm{Qb}$ pada posisi tip CDL di intraatrial lebih tinggi dibandingkan pada posisi tip CDL di CAJ, namun perbedaan ini bukan berarti posisi tip CDL di intraatrial lebih baik daripada di CAJ karena perbedaan ini $(3,8 \%)$ tidak akan memberikan perubahan nilai $\mathrm{Qb}$ yang berarti.

Rekomendasi terakhir dari KDOQI, yaitu posisi tip kateter berada di midatrium kanan dengan lumen arterial menghadap ke mediastinum untuk mencegah resirkulasi darah dan menghindari komplikasi jika tip kateter berada di vena kava superior. ${ }^{18}$ Penelitian yang dilakukan oleh Mandolfo et $\mathrm{al}^{19}$ menunjukkan bahwa posisi tip kateter di bagian tengah atrium kanan memiliki nilai $\mathrm{Qb}$ ang lebih tinggi dibandingkan posisi tip kateter di vena cava superior dan inferior. Penelitian yang dilakukan oleh Millan et $\mathrm{al}^{20}$ menyatakan bahwa tidak terdapat perbedaan yang bermakna secara statistik antara angka mortalitas pasien dengan posisi tip CDL di atrium kanan dan pasien dengan posisi tip CDL di vena cava superior.

Cavoatrial junction juga menjadi lokasi tip kateter pada beberapa penelitian. Lokasi ini berada pada posisi yang lebih proksimal dengan aliran darah lebih tinggi yang dapat mencegah terjadinya trombosis dan aritmia karena berada di luar atrium. ${ }^{18,21}$ Natsir $^{22}$ melaporkan bahwa pasien dengan posisi tip CDL di CAJ memiliki nilai Qb yang lebih tinggi (>300 $\mathrm{ml} / \mathrm{menit})$ dibandingkan pasien dengan posisi tip CDL di vena kava superior ( $<300 \mathrm{ml} / \mathrm{menit}$ ). Sampai saat ini belum ada penelitian yang membahas tentang perbedaan nilai $\mathrm{Qb}$ pada posisi tip CDL di intraatrial dan di CAJ maupun penelitian yang menunjukkan terdapat hubungan bermakna antara posisi tip CDL di intraatrial dan di CAJ dengan nilai Qb.

Rekomendasi lain menyatakan bahwa tip kateter tidak boleh diletakkan terlalu dalam di atrium kanan karena dapat menyebabkan pembentukan trombus, perforasi, dan aritmia. Tip kateter juga tidak dapat diletakkan terlalu tinggi yaitu di vena kava superiorkarena dapat menyebabkan oklusi vena tersebut, malfungsi kateter, dan meningkatnya kejadian resirkulasi. Tal et $\mathrm{al}^{23}$ menekankan tip fungsional sebagai bagian yang penting dalam keberhasilan dialisis. Tip fungsional ialah bagian dari kateter mulai dari lumen paling proksimal sampai ke bagian tip dari kateter. Tip fungsional ini yang memegang peranan penting dalam proses dialisis sehingga direkomendasikan untuk meletakkan kateter sampai seluruh bagian tip fungsional berada di dalam atrium kanan. Pemantauan tip kateter dengan radiografi secara rutin sangat diperlukan dikarenakan sering terjadinya pergerakan dari tip kateter akibat tipe kateter, lokasi insersi, pergerakan dari pasien, posisi lengan, fase respirasi, dan akibat prosedur radiografi itu sendiri. ${ }^{15}$ 


\section{SIMPULAN}

Berdasarkan hasil penelitian ini dapat disimpulkan bahwa terdapat korelasi yang tidak bermakna secara statistik antara posisi tip CDL dengan nilai $\mathrm{Qb}$ dimana nilai rerata $\mathrm{Qb}$ posisi tip $\mathrm{CDL}$ di intraatrial $(178,2 \mathrm{ml} / \mathrm{menit})$ sedikit lebih tinggi daripada rerata nilai $\mathrm{Qb}$ posisi tip CDL di CAJ (171,6 ml/menit).

\section{SARAN}

Disarankan untuk melakukan penelitian dengan variabel yang berbeda seperti diameter dan panjang kateter, serta faktorfaktor risiko yang lain.

\section{DAFTAR PUSTAKA}

1. Pusat Data dan Informasi Kemenkes RI. Situasi Penyakit Ginjal Kronis. Infodatin [Internet]. 2017; Available from: http://www.pusdatin.kemkes. go.id/article/view/17050400002/situasipenyakit-ginjal-kronis.html

2. IRR. 8th Report of Indonesian Renal Registry 2015. 2015.

3. Chang KY, Kim S-H, Kim YO, Jin DC, Song HC, Choi EJ, et al. The impact of blood flow rate during hemodialysis on all-cause mortality. Korean J Intern Med [Internet]. 2016;31(6):1131-9.

4. Peynircioglu B, Ozkan F, Canyigit M, Cil BE, Balkanci F. Tunneled internal jugular catheters in adult patients: Comparison of outcomes in hemodialysis versus infusion catheters. Acta Radiol. 2007;48(6):613-9.

5. Canaud B. Vascular access for intermittent renal replacement therapy. In: Critical Care Nephrology (2nd ed). Philadelphia: Saunders Elsevier, 2009; p. 1207-12.

6. Vesely TM. Central venous catheter tip position: A continuing controversy. J Vasc Interv Radiol. 2003;14(5):527-34.

7. Mallappallil M, Friedman E, Delano B, McFarlane S, Salifu M. Chronic kidney disease in the elderly: evaluation and management. Clin Pr. 2014;11(5):525-35.

8. Santoro D, Benedetto F, Mondello P, Pipit N, Barill D, Spinelli F, et al. Vascular access for hemodialysis: Current perspectives. Int $\mathbf{J}$ Nephrol Renovasc Dis. 2014;7:281-94.
9. Leś J, Wańkowicz Z. Methods of central vascular access for haemodialysis. Anaesthesiol Intensive Ther. 2013; 45(3): 18066.

10. Timsit J-F. What is the best site for central venous catheter insertion in critically ill patients ? Crit Care. 2003;7(6):397-9.

11. Canaud B. Vascular access for continuous renal replacement therapy. In: Critical Care Nephrology (2nd ed). Philadelphia: Saunders Elsevier, 2009. p. 1336-41.

12. Ghali E, Malik A. Effect of blood flow rate on dialysis adequacy in Al-Kadhimiya Teaching Hospital. Iraqi $\mathbf{J}$ Med Sci. 2012;10(3):260-4.

13. Vesely TM. The challenges of hemodialysis catheter use. Endovasc Today. June 2013;60-2.

14. Marques MG, Maia $P$, Ponce $P$. Dialysis catheter malfunction. Port J Nephrol Hypert. 2017;31(9):184-91.

15. Gilman M. Thoracic lines and tubes. In: Thoraric Imaging: The Requisites (3rd ed.). Philadelphia: Elsevier, 2019; p. 210-25.

16. Shahdadi H, Haghighi M, Moghadam MP, Balouchi A. Efficiency of high blood flow in increasing dialysis efficacy versus dialysis efficiency of high blood flow in increasing dialysis efficacy versus dialysis complications. Indian J Public Health Res Dev. 2017;8(1):24650.

17. Borzou SR, Gholyaf M, Zandiha M, Amini R, Goodarzi MT, Torkaman B. The effect of increasing blood flow rate on dialysis adequacy in hemodialysis patients. Saudi J Kidney Dis Transp. 2009;20(4):639-42.

18. Tawk S, Barakat E, Hammer F. A proposed simple and accurate technique for optimal long-term hemodialysis catheter tip placement. J Belg Soc Radiol. 2018;102(1):21.

19. Mandolfo S, Galli F, Gaggia P. Factors influencing permanent catheter. J Vasc Access. 2001;2:106-9.

20. Millan JT, Lopez MT, Serna MB. Location of the central venous catheter tip in the right atrium: description in 2348 critical patients. Med Intensiva. 2010;34(9): 595-9.

21. Bannon M, Heller S, Rivera M. Anatomic considerations for central venous 
cannulation. Dove Med Press J. 2011; 4:27-39.

22. Natsir O. Korelasi posisi tip catheter double lumen dengan kelancaran dan kenyamanan hemodialisa pada pemasangan CDL tunneling. Jakarta: Fakultas
Kedokteran Universitas Indonesia; 2015.

23. Tal M, Friedman T, Mojibian H. Dialysis catheter tip placement: the functional tip. Endovasc Today. 2013;(6):73-5. 